\title{
Diversity of Extended Spectrum $\beta$-lactamases among Multi Drug Resistant Clinical Isolates of Pseudomonas aeruginosa Collected fromTertiary Care Hospitals of Peshawar, Pakistan
}

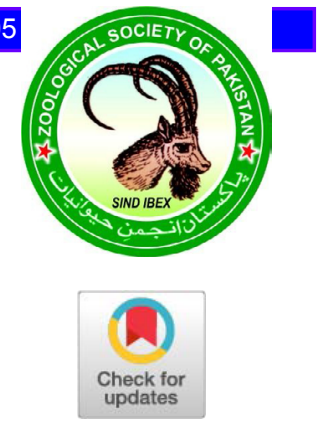

\author{
Amjad Ali, Kafeel Ahmad*and Shaista Rahat \\ Centre of Biotechnology and Microbiology, University of Peshawar, Pakistan
}

\begin{abstract}
A B S T R A C T
Pseudomonas aeruginosa is an opportunistic pathogen and the leading cause of nosocomial infection worldwide. This bacterium produces enzymes known as extended spectrum $\beta$-lactamases which render broad spectrum cephalosporins and penicillins inactive. This study reports antibiotic susceptibility pattern, multiple antibiotic resistance (MAR) index and prevalence of extended spectrum $\beta$-lactamases among clinical isolates of $P$. aeruginosa collected from tertiary care hospitals of Peshawar, Pakistan. A total of 187 P. aeruginosa isolates were collected. Antibiotic susceptibility was evaluated by Kirby Bauer disc diffusion method using nineteen different antibiotics and multiple antibiotic resistance (MAR) index was determined. Prevalence of extended spectrum $\beta$-lactamases was studied by double disc synergy test. The ESBL genes blaCTX-M, blaOXA-10, blaPER-1, blaSHV and blaTEM were analyzed by PCR amplification among the isolates. Susceptibility to antibiotics was: imipenem $(85.02 \%)$, meropenem $(82.88 \%)$, cefepime $(76.47 \%)$, piperacillin-tazobactam $(76.47 \%)$, colistin $(74.86 \%)$, ciprofloxacin $(74.33 \%)$, piperacillin $(72.19 \%)$, ceftazidime $(68.98 \%)$, ofloxacin $(68.44 \%)$, amikacin $(66.84 \%)$, cefoperazone $(66.31 \%)$, carbenicillin $(66.31 \%)$, gentamicin $(64.7 \%)$, tobramycin $(64.7 \%)$, aztreonam $(52.4 \%)$, ticarcillin $(42.78 \%)$, ceftriaxone $(32.08 \%)$, cefotaxime $(15.5 \%)$, amoxicillin-clavulanic acid $(6.41 \%)$. A total of $36.89 \%(n=69)$ isolates showed multi drug resistance. The MAR index of $34.22 \%$ $(\mathrm{n}=64)$ isolates was higher than 0.2. Phenotypic ESBL production was observed in $21.39 \%(\mathrm{n}=40)$ isolates. Prevalence of blaOXA-10, blaCTX-M, blaTEM and blaSHV was $36.89 \%(\mathrm{n}=69), 20.85 \%(\mathrm{n}=39), 5.34 \%$ $(\mathrm{n}=10)$ and $3.2 \%(\mathrm{n}=6)$ respectively. PER-1 gene was not detected. Resistance to antibiotics is increasing in P. aeruginosa which is a matter of concern and needs proper management. Non-selective and over use of antibiotics should be avoided and proper control measures should be taken to avoid the spread of these multi-drug resistant strains.
\end{abstract}

\begin{tabular}{l} 
Article Information \\
Received 12 July 2019 \\
Revised 30 September 2019 \\
Accepted 28 January 2020 \\
Available online 19 March 2021 \\
Authors' Contribution \\
\hline AA conducted the experiments, \\
compiled the data and wrote the \\
manuscript. SR contributed towards \\
manuscript writing and proof reading. \\
KA designed the project, supervised \\
the work, contributed towards data \\
analysis, manuscript writing and proof \\
reading. \\
Key words \\
Pseudomonas aeruginosa, MDR, MAR \\
Index, ESBL, blaOXA-10, blaCTX-M, \\
blaPER-1, blaTEM, blaSHV
\end{tabular}

\section{INTRODUCTION}

$P$ eudomonas aeruginosa is one of the main causes of nosocomial infections like burn infections, wounds infections, urinary tract infections, pneumonia, bacteremia, otitis externa, endophthalmitis, meningitis and infections in cystic fibrosis patients (Branski et al., 2009). These infections could develop into more severe form in immune compromised patients like cancer and neutropenic patients (Bodey et al., 1983). The global emergence of multi-drug resistant $P$. aeruginosa is serious health issue as $P$. aeruginosa resistant to several classes of antibiotics such as penicillin, cephalosporin, aminoglycoside, quinolone and carbapenem have been reported (Dundar and Otkun, 2010). Antimicrobial resistance mechanisms in $P$. aeruginosa include multidrug efflux pumps, outer

\footnotetext{
Corresponding author: kafeelpbg@gmail.com 0030-9923/2021/0003-0885 \$ 9.00/0

Copyright 2021 Zoological Society of Pakistan
}

membrane impermeability to antibiotics, enzymatic degradation of antibiotics and target site modification (Lambert, 2002; Mesaros et al., 2007). Production of extended spectrum beta lactamases (ESBLs) by $P$. aeruginosa is an important mechanism to inactive antibiotics. These enzymes could hydrolyze penicillins, extended spectrum cephalosporins such as, ceftriaxone, ceftazidime, cefotaxime and the monobactam aztreonam (Paterson and Bonomo, 2005; Khanfar et al., 2009). However, they have no effect on cephamycins or carbapenems and their activity is inhibited by clavulanic acid (Paterson and Bonomo, 2005). The global spread of ESBL producing $P$. aeruginosa pose a serious health threat.

Extended spectrum $\beta$-lactamase producing bacteria were first reported in Germany in 1983 (Knothe et al., 1983). Different variants of ESBLs such as TEM, PER, SHV, GES, VEB and CTX-M have been reported in $P$. aeruginosa of different geographical origins (Aktas et al., 2005; Al Naiemi et al., 2006; Celenza et al., 2006; Zhao and $\mathrm{Hu}, 2010)$. Cefotaximase-Munich (CTX-M) 
beta lactamase was first isolated from Escherichia coli recovered from ear exudate of newly born baby in Munich, Germany (Bauernfeind et al., 1990). These $\beta$ lactamases have been divided into five groups based on amino acid sequence i.e. CTX-M-1, CTX-M-2, CTX-M-8, CTX-M-9 and CTX-M-25 (Paterson and Bonomo, 2005; Gupta, 2007). All these CTX-M $\beta$ lactamases have been reported from different countries including Japan, Germany, Argentina, Poland, Taiwan, France, Spain, Brazil, China, Korea and Canada (Canton et al., 2012). These enzymes possess hydrolytic activity against cefotaxime and have approximately $40 \%$ or less identity with other $\beta$-lactamases such as TEM and SHV (Paterson and Bonomo, 2005). Oxacillinases (OXA) are $\beta$-lactamases that could hydrolyze oxacillin and have been reported in $P$. aeruginosa (Naas et al., 2008; El-Shouny et al., 2018; Odumosu et al., 2016). The OXA type variants, OXA-10 and OXA-13, weakly hydrolyze cephalosporin (cefotaxime and ceftriaxone) and aztreonam (Naas et al., 2008). The Pseudomonas extended resistance (PER-1) $\beta$-lactamase of $P$. aeruginosa can efficiently hydrolyze third generation cephalosporins, penicillins and aztreonam but has no effect on cephamycins and carbapenems (Aktas et al., 2005; Nordmann and Naas, 1994; Opus et al., 2017; Qing et al., 2014). Sulfhydryl variable (SHV) type $\beta$-lactamases i.e. SHV-1 efficiently hydrolyze cefotaxime but slightly hydrolyze ceftazidime (Paterson and Bonomo, 2005). More than 50 SHV $\beta$-lactamases have been identified which are derived either from SHV-1 or SHV-2 (Paterson and Bonomo, 2005; Gupta, 2007; Peymani et al., 2017). In 1965, TEM-1 $\beta$-lactamase was first confirmed in Escherichia coli isolated from a patient named Temoneira in Athens (Datta and Kontomichalou, 1965). Such $\beta$-lactamases could hydrolyze $\beta$-lactam antibiotics such as penicillins and cephalosporins (Salverda et al., 2010; Hassuna et al., 2015). The spread of multiple antibiotic resistant $P$. aeruginosa in hospital environments has been reported across the world (Krumperman, 1983; Paul et al., 1997).

Infectious diseases are highly prevalent in Pakistan, however; there is scarcity of data on genotypic characteristics of locally prevalent bacterial pathogens. This study was aimed at investigating phenotypic and genotypic characterization of extended spectrum beta lactamases among clinical isolates of $P$. aeruginosa isolated from different clinical specimens in tertiary care hospitals of Peshawar, Khyber Pakhtunkhwa Pakistan.

\section{MATERIALS AND METHODS}

\section{Bacterial isolates}

A total of $187 P$. aeruginosa isolates were collected from clinical specimens in tertiary care hospitals of
Peshawar, Pakistan during 2014-2016. Among these, 74 isolates were recovered from pus, 34 from urine, 24 from sputum, 21 from wound, 12 from bronchial wash, 8 from cerebrospinal fluid, 6 from blood, 5 from high vaginal swab and 3 from diabetic foot. The cultures were grown on MacConkey agar (Oxoid, UK). Pure isolates were identified as $P$. aeruginosa using morphological and biochemical tests (Parija, 2006).

\section{Antibiotic sensitivity}

Antibiotic sensitivity was evaluated using Kirby Bauer disc diffusion method as suggested by the Clinical Laboratory Standard Institute (Clinical Laboratory Standard Institute, 2007; Clinical Laboratory Standard Institute, 2014). The antibiotics (Oxoid, UK) used were: Amoxicillin-clavulanic acid $(30 \mu \mathrm{g})$, Cefotaxime $(30 \mu \mathrm{g})$, Piperacillin-tazobactam $(110 \mu \mathrm{g})$, Cefoperazone $(75 \mu \mathrm{g})$, Ceftazidime $(30 \mu \mathrm{g})$, Ceftriaxone $(30 \mu \mathrm{g})$, Gentamicin $(10$ $\mu \mathrm{g})$, Meropenem $(10 \mu \mathrm{g})$, Cefepime $(30 \mu \mathrm{g})$, Aztreonam (30 $\mu \mathrm{g})$, Carbenicillin $(100 \mu \mathrm{g})$, Imipenem $(10 \mu \mathrm{g})$, Ticarcillin $(75 \mu \mathrm{g})$, Piperacillin $(100 \mu \mathrm{g})$, Amikacin $(30$ $\mu \mathrm{g})$, Ciprofloxacin $(5 \mu \mathrm{g})$, Tobramycin $(10 \mu \mathrm{g})$, Ofloxacin $(5 \mu \mathrm{g})$ and Colistin $(10 \mu \mathrm{g})$. Bacterial colonies were suspended in normal saline and turbidity was adjusted by comparing with $0.5 \mathrm{McFarland}$ standard. Bacterial suspension was inoculated on Muller Hinton agar (Oxoid, UK) plate and discs were placed on the medium at equal distances. The cultures were incubated at $37{ }^{\circ} \mathrm{C}$ for $18-24$ hrs. and zones of inhibition were measured.

\section{Determination of multiple antibiotic resistance index}

Multiple antibiotic resistance index for each isolate of $P$. aeruginosa was determined using the formula, MAR index= $a / b$ where ' $a$ ' represent the number of antibiotics to which isolate show resistant, where ' $b$ ' represent total number of antibiotics used (Krumperman, 1983; Sandhu et al., 2016).

Phenotypic detection of extended spectrum $\beta$-lactamases

Double disc synergy test was used for detection of ESBLs production (Jarlier et al., 1998). Bacterial lawn was made on Muller Hinton Agar and amoxicillin-clavulanic acid disc was applied in the center. Discs of aztreonam, cefepime, cefotaxime and ceftazidime were placed 15-20 $\mathrm{mm}$ away from the disc of amoxicillin-clavulanic acid. The plates were incubated at $37^{\circ} \mathrm{C}$ for $18 \mathrm{~h}$ and inhibition zones were measured. Increase in size of inhibition zone around one or more cephalosporin discs and aztreonam towards amoxicillin-clavulanic acid disc showed presence of ESBL production.

\section{DNA extraction}

GeneJET Genomic DNA purification kit (Thermo Scientific, Lithuania, \#K0721) was used for isolation of 
bacterial genomic DNA. Isolated DNA was preserved at $-20^{\circ} \mathrm{C}$.

\section{Molecular detection of ESBLS}

Previously reported primers were used for the amplification of blaCTX-M, blaOXA-10, blaPER-1, blaSHV, and blaTEM genes (Farshadzadeh et al., 2014; Peerayeh et al., 2014). PCR reaction mix (25 $\mu$ l) contained $12.5 \mu \mathrm{l}$ SuperHot Master Mix (BIORON, Cat. No. 119102), $1 \mu \mathrm{l}$ of each primer $(0.5 \mu \mathrm{M}), 1 \mu 1$ genomic DNA and $9.5 \mu \mathrm{l}$ molecular grade water (Sigma-Aldrich, US). Reaction conditions consisted of initial denaturation $(95$ ${ }^{\circ} \mathrm{C}$ for $\left.5 \mathrm{~min}\right)$, followed by 30 cycles of denaturation $\left(94{ }^{\circ} \mathrm{C}\right.$ for $1 \mathrm{~min})$, annealing $\left(55^{\circ} \mathrm{C}\right.$ for blaCTX-M and blaTEM; $57{ }^{\circ} \mathrm{C}$ for blaOXA-10; $48{ }^{\circ} \mathrm{C}$ for blaPER-1; $60{ }^{\circ} \mathrm{C}$ for blaSHV) and extension $\left(72^{\circ} \mathrm{C}\right.$ for $\left.1 \mathrm{~min}\right)$. Final extension was carried out at $72{ }^{\circ} \mathrm{C}$ for $5 \mathrm{~min}$. PCR products were analyzed using agarose gel (1.5\%) and $100 \mathrm{bp}$ DNA ladder (BIORON, Cat. No. 304105) was used as size marker.

Table I. Antimicrobial susceptibility of Pseudomonas aeruginosa isolates.

\begin{tabular}{lllll}
\hline $\begin{array}{l}\text { S. } \\
\text { No. }\end{array}$ & $\begin{array}{l}\text { Antimi- } \\
\text { crobial }\end{array}$ & $\begin{array}{l}\text { Susceptible, } \\
\text { No. (\%) }\end{array}$ & $\begin{array}{l}\text { Intermediate, } \\
\text { No. (\%) }\end{array}$ & $\begin{array}{l}\text { Resistant, } \\
\text { No. (\%) }\end{array}$ \\
\hline 1. & TZP & $143(76.47 \%)$ & $26(13.90 \%)$ & $18(9.62 \%)$ \\
2. & AMC & $12(6.41 \%)$ & $20(10.69 \%)$ & $155(82.88 \%)$ \\
3. & CTX & $29(15.50 \%)$ & $80(42.78 \%)$ & $78(41.71 \%)$ \\
4. & CAZ & $129(68.98 \%)$ & $7(3.74 \%)$ & $51(27.27 \%)$ \\
5. & CRO & $60(32.08 \%)$ & $56(29.94 \%)$ & $71(37.96 \%)$ \\
6. & CFP & $124(66.31 \%)$ & $20(10.69 \%)$ & $43(22.99 \%)$ \\
7. & FEP & $143(76.47 \%)$ & $6(3.20 \%)$ & $38(20.32 \%)$ \\
8. & ATM & $98(52.40 \%)$ & $49(26.20 \%)$ & $40(21.39 \%)$ \\
9. & IPM & $159(85.02 \%)$ & $3(1.60 \%)$ & $25(13.36 \%)$ \\
10. & MEM & $155(82.88 \%)$ & $0(0 \%)$ & $32(17.11 \%)$ \\
11. & TIC & $80(42.78 \%)$ & $58(31.01 \%)$ & $49(26.20 \%)$ \\
12. & PIP & $135(72.19 \%)$ & $32(17.11 \%)$ & $20(10.69 \%)$ \\
13. & CB & $124(66.31 \%)$ & $12(6.41 \%)$ & $51(27.27 \%)$ \\
14. & CN & $121(64.70 \%)$ & $17(9.09 \%)$ & $49(26.20 \%)$ \\
15. & AK & $125(66.84 \%)$ & $16(8.55 \%)$ & $46(24.59 \%)$ \\
16. & TOB & $121(64.70 \%)$ & $14(7.48 \%)$ & $52(27.80 \%)$ \\
17. & CIP & $139(74.33 \%)$ & $7(3.74 \%)$ & $41(21.92 \%)$ \\
18. & OFX & $128(68.44 \%)$ & $11(5.88 \%)$ & $48(25.66 \%)$ \\
19. & CT & $140(74.86 \%)$ & $0(0 \%)$ & $47(25.13 \%)$ \\
\hline A. & An &
\end{tabular}

AMC, Amoxicillin-clavulanic acid $(30 \mu \mathrm{g})$; CTX, Cefotaxime $(30 \mu \mathrm{g})$, TZP, Piperacillin-tazobactam $(110 \mu \mathrm{g})$; CFP, Cefoperazone $(75 \mu \mathrm{g})$; CAZ, Ceftazidime $(30 \mu \mathrm{g})$; CRO, Ceftriaxone $(30 \mu \mathrm{g})$; CN, Gentamicin $(10 \mu \mathrm{g})$; MEM, Meropenem $(10 \mu \mathrm{g})$; FEP, Cefepime (30 $\mu \mathrm{g})$; ATM, Aztreonam $(30 \mu \mathrm{g})$; CB, Carbenicillin $(100 \mu \mathrm{g})$; IPM, Imipenem $(10 \mu \mathrm{g})$; TIC, Ticarcillin $(75 \mu \mathrm{g})$; PIP, Piperacillin $(100 \mu \mathrm{g})$; AK, Amikacin $(30$ $\mu \mathrm{g})$; CIP, Ciprofloxacin $(5 \mu \mathrm{g})$; TOB, Tobramycin $(10 \mu \mathrm{g})$; OFX, Ofloxa$\operatorname{cin}(5 \mu \mathrm{g})$ and $\mathrm{CT}$, Colistin $(10 \mu \mathrm{g})$.

\section{RESULTS}

Antibiotic sensitivity data is given in Table I. Resistance to cephalosporin third generation antimicrobials cefoperazone, ceftazidime, ceftriaxone and cefotaxime were $22.99 \%, 27.27 \%, 37.96 \%$ and $41.71 \%$, respectively. Resistance to cephalosporin fourth generation cefepime was $20.32 \%$. Resistance to pencillins antimicrobials i.e. piperacillin, ticarcillin and carbenicillin was $10.69 \%, 26.2 \%$ and $27.27 \%$, respectively. Resistance to aminoglycoside antimicrobials amikacin, gentamicin and tobramycin was $24.59 \%, 26.2 \%$ and $27.8 \%$, respectively. Resistance to fluoroquinolones antibiotics i.e. ciprofloxacin and ofloxacin was $21.92 \%$ and $25.66 \%$, respectively. Resistance to carbapenem antimicrobials imipenem and meropenem was $13.36 \%$ and $17.11 \%$, respectively. Resistance to monobactam antibiotic aztreonam was $21.39 \%$. Resistance to polymyxin antibiotic colistin was $25.13 \%$. All imipenem resistant isolates of $P$. aeruginosa were susceptible to colistin.

Table II. Prevalence of MDR isolates of Pseudomonas aeruginosa in different samples.

\begin{tabular}{lll}
\hline $\begin{array}{l}\text { S. } \\
\text { No }\end{array}$ & Specimen type & $\begin{array}{l}\text { MDR P. aeruginosa } \\
(\mathbf{n}, \mathbf{\%}),(\mathbf{n}=\mathbf{6 9})\end{array}$ \\
\hline 1. & Pus & $30(43.47)$ \\
2. & Urine & $11(15.94)$ \\
3. & Sputum & $06(8.69)$ \\
4. & Wound & $10(14.49)$ \\
5. & Bronchial wash & $05(7.24)$ \\
6. & Blood & $03(4.34)$ \\
7. & Cerebrospinal fluid & $04(5.79)$ \\
\hline
\end{tabular}

Table III. MAR index of Pseudomonas aeruginosa isolates $(\mathbf{n}=187)$.

\begin{tabular}{ll}
\hline MAR index & Number of isolates, (\%) \\
\hline 0 & $27(14.43)$ \\
0.05 & $41(21.92)$ \\
0.10 & $34(18.18)$ \\
0.2 & $21(11.22)$ \\
0.3 & $14(7.48)$ \\
0.4 & $13(6.95)$ \\
0.5 & $5(2.67)$ \\
0.6 & $10(5.34)$ \\
0.7 & $11(5.88)$ \\
0.8 & $5(2.67)$ \\
0.9 & $6(3.2)$ \\
\hline
\end{tabular}


A total of $36.89 \%(n=69)$ isolates showed multiple drug resistance (MDR) having resistance against three or more drug classes (Table II). Multiple antibiotic resistance (MAR) index values for isolates of $P$. aeruginosa are given in Table III and Table IV. In total, 34.22\% $(\mathrm{n}=64)$ isolates showed MAR index greater than 0.2 and $54.54 \%$ $(\mathrm{n}=102)$ isolates showed MAR index value less than 0.2 . Source wise MAR index of higher than 0.2 for the isolates was: blood (4.68\% isolates), cerebrospinal fluid (6.25\%), bronchial wash $7.81 \%$ ), sputum $(9.37 \%)$, wound $(14.06 \%)$, urine $(15.62 \%)$ and pus $(42.18 \%)$ as shown in Table IV. Highest multiple antibiotic resistance index (MARI) of 0.9 was observed for six isolates that were resistant to all tested antibiotics except colistin.

Table IV. Distribution of Pseudomonas aeruginosa isolates based on MARI value $>0.2$ among different clinical specimens.

\begin{tabular}{lll}
\hline Specimen type & $\begin{array}{l}\text { Isolates with MAR } \\
\text { Index }>\mathbf{0 . 2}(\mathbf{n}=\mathbf{6 4})\end{array}$ & $\begin{array}{l}\text { Percentage } \\
\mathbf{( \% )}\end{array}$ \\
\hline Pus & 27 & 42.18 \\
Urine & 10 & 15.62 \\
Wound & 9 & 14.06 \\
Sputum & 6 & 9.37 \\
Bronchial wash & 5 & 7.81 \\
Cerebrospinal fluid & 4 & 6.25 \\
Blood & 3 & 4.68 \\
\hline
\end{tabular}

Table V. Phenotypically ESBL positive strains of $P$. aeruginosa.

\begin{tabular}{llll}
\hline $\begin{array}{l}\text { S. } \\
\text { No. }\end{array}$ & $\begin{array}{l}\text { No of } \boldsymbol{P} \text { aerugi- ESBL positive } \boldsymbol{P} . \\
\text { nosa } \text { isolates } \\
=\mathbf{1 8 7} \text { (n } \text { aeruginosa } \text { isolates } \\
(\mathbf{n}=\mathbf{4 0}), \mathbf{n}(\mathbf{\%}),\end{array}$ \\
\hline 1. & Pus & 74 & $14(35 \%)$ \\
2. & Urine & 34 & $10(25 \%)$ \\
3. & Sputum & 24 & $4(10 \%)$ \\
4. & Wound & 21 & $5(12.5 \%)$ \\
5. & Bronchial wash & 12 & $3(7.5 \%)$ \\
6. & Blood & 6 & $2(5 \%)$ \\
7. & Cerebrospinal fluid & 8 & $2(5 \%)$ \\
8. & High vaginal swab & 5 & $0(0 \%)$ \\
9. & Diabetic foot & 3 & $0(0 \%)$ \\
\hline
\end{tabular}

Out of 187 isolates, $21.39 \%(n=40)$ were ESBL positive phenotypically (Fig. 1). Frequency of ESBL positive isolates was $5 \%, 5 \%, 7.5 \%, 10 \%, 12.5 \%, 25 \%$ and $35 \%$ from cerebrospinal fluid, bronchial wash, sputum, wound, urine and pus samples respectively as given in Table V. Genotypically, blaOXA-10, blaCTX-M, blaTEM and blaSHV genes were detected in $36.89 \% \quad(n=69)$, $20.85 \%(n=39), 5.34 \%$ and $3.2 \%(n=6)$ isolates respectively (Supplementary Table I, Fig. 2), however, blaPER-1 was not detected. Among phenotypically ESBL positive isolates $(\mathrm{n}=40)$, blaOXA-10, blaCTX-M, blaTEM and blaSHV were observed in $80 \%(n=32), 62.5 \%(n=25), 12.5 \%(n=5)$ and $7.5 \% \quad(n=3)$ isolates respectively (Supplementary Table I). Among phenotypically ESBL negative isolates $(\mathrm{n}=147)$, blaOXA-10, blaCTX-M, blaTEM and blaSHV were observed in $25.17 \%(n=37), 9.52 \%(n=14), 3.4 \%$ $(\mathrm{n}=5)$ and $2 \%(\mathrm{n}=3)$ isolates respectively (Supplementary Table I).

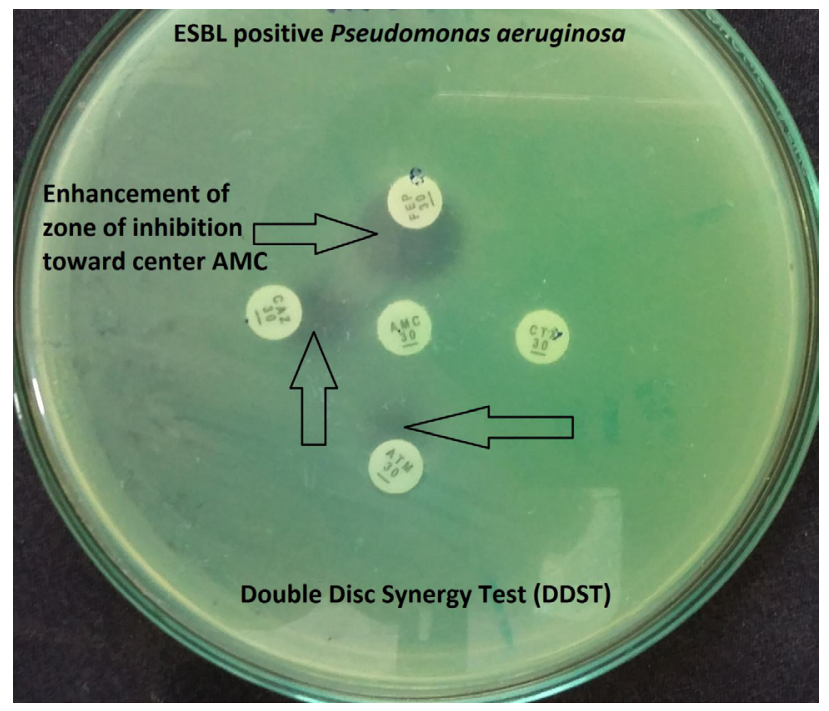

Fig. 1. Double Disc Synergy Test: ESBL positive Pseudomonas aeruginosa, the size of zones of inhibition around cefepime, ceftazidime and aztreonam are enhanced towards center amoxicillin-clavulanic acid disc as shown by arrows.

\section{DISCUSSION}

P. aeruginosa is rapidly developing resistance against the prevalent antibiotics. Previously, ESBLs producing $P$. aeruginosa has been reported from different geographical locations (Manchanda and Singh, 2003; Ghafourian et al., 2015). However, little data is available regarding ESBL producing $P$. aeruginosa prevailing in the region. Current study showed $21.39 \%$ prevalence of ESBL producing $P$. aeruginosa isolated from different clinical specimens. Isolates from pus had maximum frequency of ESBL production followed by urine, wound, sputum, bronchial wash, cerebro-spinal fluid and blood samples. These results are in harmony with the findings of Aggarwal et al. 
(2008) and Shaikh et al. (2015) who reported $20.27 \%$ and $25.13 \%$ ESBL frequency respectively among $P$. aeruginosa isolates from various clinical samples. Imipenem and meropenem are broad spectrum carbapenems commonly used effectively against extended spectrum $\beta$-lactamase
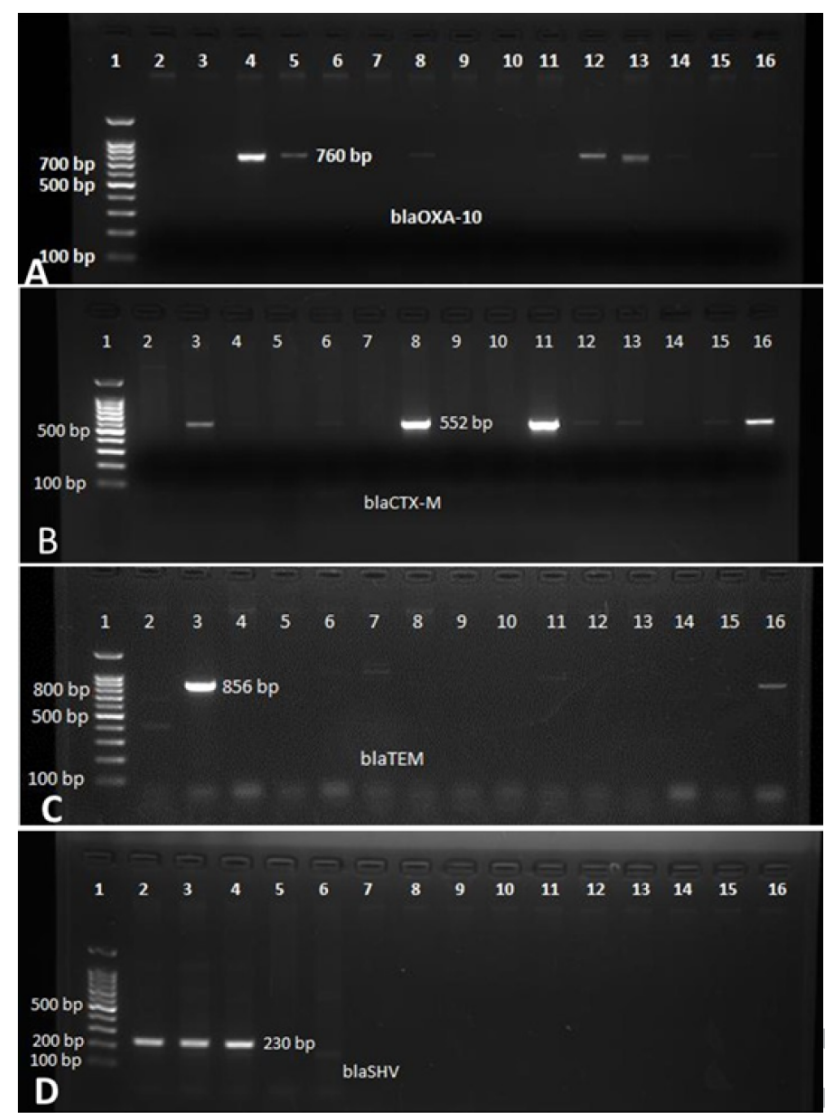

Fig. 2. A, PCR amplification of blaOXA-10 gene (A) Lane $1=100$ bp DNA ladder. Lanes 4, 5, 8, 12, 13, 14 and 16 in A show blaOXA-10 (760 bp) blaCTX-M gene; (B), Lanes $3,8,11,12,13,15$ and 16 in B show blaCTX-M (552 bp) positive blaTEM gene (C), Lanes 3 and 16 show blaTEM (856 bp) positive blaSHV gene and (D) Lanes 2 , 3 and 4 in D show blaSHV (230 bp) positive Pseudomonas aeruginosa isolates.

producing strains (Shaikh etal.,2015). These two antibiotics were found effective against most of the isolates in current study. Similar results have been reported previously (Shaikh et al., 2015; Alikhani et al., 2014). Resistance to both imipenem (13.36\%) and meropenem (17.11\%) was also observed as reported previously (Pathmanathan et al., 2009; Hong et al., 2015). In current study, 36.89\% isolates showed multi drug resistance (MDR). Ullah et al. (2009) observed 29.24\% MDR frequency among clinical isolates of $P$. aeruginosa from burn patients. Alikhani et al. (2014) observed $88.7 \%$ MDR frequency among $P$. aeruginosa isolates from west of Iran. In current study, ceftazidime was found to be the most effective (68.98\% susceptibility) antibiotic among the third generation cephalosporines. (Shahid et al. (2003) reported $83.3 \%$ susceptibility to ceftazidime in samples from North India. A low level of resistance to the aminoglycosides amikacin, gentamicin and tobramycin was observed in the current study. In contrast, a study from Isfahan reported $60 \%$ resistance to gentamicin, $62 \%$ to tobramycin and $70 \%$ to amikacin (Golshani et al., 2012). Resistance to aminoglycoside is due to acquisition of plasmids which produce aminoglycoside modifying enzymes (Hancock, 1998). These enzymes modify the aminoglycosides antibiotics by various mechanisms such as acetylation, adenylation, and phosphorylation which decrease the uptake or reduce the ribosomal interaction of enzymatically modified drugs (Hancock, 1998). In addition, the chromosome of $P$. aeruginosa has an aminoglycoside resistant gene aphA that is activated by certain mutations (Hancock, 1998). Among fluoroquinolones, ciprofloxacin showed good activity (74.33\% susceptibility) in this study. A study from France reported $68 \%$ susceptibility to ciprofloxacin (Cavallo et al., 2007). Resistance to ofloxacin and ciprofloxacin was $25.66 \%$ and $21.92 \%$ respectively in the current study. Golshani et al. (2012) reported high level of resistance to fluoroquinolones. Resistance to quinolone is because of mutations in regulatory gene mexR that regulates mexABoprM genes of efflux system and, hence, expression of efflux system genes is enhanced, and quinolone are extruded (Ziha-Zarifi et al., 1999). Among penicillins, piperacillin showed maximum activity (72.19\% susceptibility). This finding is in close agreement to the report of Llanes et al. (2013) who investigated $P$. aeruginosa isolates from cystic fibrosis in France. P. aeruginosa acquires resistance to penicillins mostly due to alteration in penicillin binding protein (Srikumar et al., 1999).

In this study, $34.22 \%(\mathrm{n}=64)$ isolates showed multiple antibiotic resistance (MAR) index value higher than 0.2. A higher MAR index value is an indication of over-use of antibiotics in a location that contributes to evolution of resistant bacteria (Krumperman, 1983; Paul et al., 1997). A study from Turkey reported a high percentage $(51.92 \%)$ of clinical isolates of $P$. aeruginosa with MAR index higher of than 0.2 (Guvensen et al., 2017). Another study from India found that $39 \%$ P. aeruginosa collected from area with high use of antibiotics had MAR index of higher than 0.2 (Bhuvaneshwari, 2017). A high MAR index value ( 0.6 to 0.9 ) was observed for 22 isolates of $P$. aeruginosa recovered from clinical specimens and hospital environment in Nigeria (Chika et al., 2017). This high MAR index was suggested to be linked to the development 
of multi drug resistant isolates of $P$. aeruginosa because of intensive use of antibiotics in Nigeria (Chika et al., 2017).

According to current findings, prevalence of blaCTX-M was $20.85 \%$. Prevalence of the gene was $10.7 \%$ among isolates of $P$. aeruginosa isolated from a hospital in Makkah, Saudi Arabia (Ahmed et al., 2015) and $19.6 \%$ among isolates of $P$. aeruginosa collected from a Brazilian tertiary care hospital (Polotto et al., 2012). A high frequency of blaOXA-10 gene was observed in this study that is in agreement with previous reports (Weldhagen et al., 2003; Poirel et al., 2001; Neyestanaki et al., 2014). Low prevalence $(5.34 \%)$ of blaTEM was observed in this study in contrast to previous reports from Iran (61\%) and China (20.5\%) (Neyestanaki et al., 2014; Chen et al., 2015). Low prevalence (3.2\%) of blaSHV was observed in this study. Previous reports from Iran and India showed $36 \%$ and $1.78 \%$ prevalence of blaSHV respectively (Toupkanlou et al., 2015; Bharti et al., 2016). According to our knowledge; this is the first report on prevalence of blaOXA-10, blaCTX-M, blaTEM and blaSHV in clinical isolates of $P$. aeruginosa collected from regional hospitals.

\section{CONCLUSIONS}

In conclusion, the prevalence of ESBL producing MDR $P$. aeruginosa of clinical origin was confirmed in the region. These findings demand for controlled use of antibiotics and proper management strategies both at community level and in hospital environments to prevent the dissemination of these resistant bacteria.

\section{ACKNOWLEDGMENT}

The financial support provided by Higher Education Commission (HEC) Islamabad, Pakistan under the "Indigenous PhD Fellowships for 5000 scholar phase-II" is deeply acknowledged.

\section{Supplementary material}

There is supplementary material associated with this article. Access the material online at: https://dx.doi. org/10.17582/journal.pjz/20190712160705

\section{Statement of conflict of interest}

The authors declare there is no conflict of interest.

\section{REFERENCES}

Aggarwal, R., Chaudhary, U. and Bala, K., 2008. Detection of extended-spectrum $\beta$-lactamase in Pseudomonas aeruginosa. Indian $J$. Pathol. Microbiol., 5: 222-224. https://doi. org/10.4103/0377-4929.41693

Ahmed, O.B., Asghar, A.H. and Bahwerth, F.S., 2015. Prevalence of ESBL genes of Pseudomonas aeruginosa strains isolated from Makkah hospitals, Saudi Arabia. Eur. J. Biol. med. Sci. Res., 3: 12-18.

Aktas, Z., Poirel, L., Salcioglu, M., Ozcan, P.E., Midilli, K., Bal, C., Ang, O. and Nordmann, P., 2005. PER1 and OXA-10 like beta lactamases in Ceftazidimeresistant Pseudomonas aeruginosa isolates from intensive care unit patients in Istanbul, Turkey. Clin. Microbial. Infect., 11: 193-198. https://doi. org/10.1111/j.1469-0691.2004.01067.x

Al Naiemi, N., Duim. B. and Bart, A.A., 2006. CTX-M extended spectrum beta lactamases in Pseudomonas aeruginosa and Stenoprophomonas maltophilia. J. med. Microbiol., 55: 1607-1608. https://doi. org/10.1099/jmm.0.46704-0

Alikhani, M.Y., Tabar, Z.K., Mihani, F., Kalantar, E., Karami, P., Sadeghi, M., Khosroshahi, S.A. and Farajnia, S., 2014. Antimicrobial resistance patterns and prevalence of blaPER-1 and blaVEB-1 genes among ESBL producing Pseudomonas aeruginosa isolates in West of Iran. Jundishapur J. Microbiol., 7: 1-5. https://doi.org/10.5812/jjm.8888

Bauernfeind, A., Grimm, H. and Schweighart, S., 1990. A new plasmidic cefotaximase in a clinical isolates of Escherichia coli. Infection, 18: 294-298. https:// doi.org/10.1007/BF01647010

Bharti, M.N. and Sharma, P.C., 2016. Molecular characterization of Pseudomonas aeruginosa isolates recovered from human patients in Himachal Pradesh (INDIA) for selective genes: Extended spectrum $\beta$-lactamases (ESBL), ampicillin class $\mathrm{C}$ (AMPC) and metallo $\beta$-lactamases (MBL) genes. Int. J. Pharm. Sci. Res., 7: 4905-4916.

Bhuvaneshwari, G., 2017. Multiple antibiotic resistance indexing of non-fermenting Gram negative bacilli. Asian J. Pharm. clin. Res., 10: 78-80. https://doi. org/10.22159/ajpcr.2017.v10i6.17717

Bodey, G.P., Bolivar, R., Fainstein, V. and Jadeja, L., 1983. Infections caused by Pseudomonas aeruginosa. Rev. Infect. Dis., 5: 279-313. https:// doi.org/10.1093/clinids/5.2.279

Branski, L.K., Al-Mousawi, A., Rivero, H., Jeschke, M.G., Sanford, A.P. and Herndon, D.N., 2009. Emerging infections in burns. Surg. Infect., 10: 389-397. https://doi.org/10.1089/sur.2009.024

Canton, R., González-Alba, J.M. and Galán, J.C., 2012. CTX-M enzymes: origin and diffusion. Front. Microbiol., 3: 1-19. https://doi.org/10.3389/ 
fmicb.2012.00110

Cavallo, J.D., Hocquet, D., Plesiat, P., Fabre, R. and Delvallez, M.R., 2007. Susceptibility of Pseudomonas aeruginosa to antimicrobials: a 2004 French multicentre hospital study. $J$. Antimicrob. Chemother., 59: 1021-1024. https:// doi.org/10.1093/jac/dkm076

Celenza, G., Pellegrini, C., Caccamo, M., Segatore, B., Amicosante, G. and Perilli M., 2006. Spread of bla CTX-M-type and bla PER-2 beta lactamase genes in clinical isolates from Bolivian hospitals. J. Antimicrob. Chemother., 57: 975-978. https://doi. org/10.1093/jac/dk1055

Chen, Z., Niu, H., Chen, G., Li, M., Li, M. and Zhou, Y., 2015. Prevalence of ESBLs-producing Pseudomonas aeruginosa isolates from different wards in a Chinese teaching hospital. Int. J. clin. exp. Med., 8: 19400-19405.

Chika, E.O., Nneka, A.R., Dorothy, O.N. and Chika, E., 2017. Multi drug resistant Pseudomonas aeruginosa isolated from hospitals in Onitsha, South-Eastern Nigeria. Int. Arch. BioMed. Clin. Res., 3: 22-26. https://doi.org/10.21276/iabcr.2017.3.3.7

Clinical Laboratory Standard Institute, 2007. Performance standards for antimicrobial susceptibility testing: Seventeenth Informational Supplement. M100-S17. Wayne, PA.

Clinical Laboratory Standard Institute, 2014. Performance standards for antimicrobial susceptibility testing: Twenty fourth Informational Supplement. M100-S24. Wayne, PA.

Datta, N. and Kontomichalou, P., 1965. Penicillinase synthesis controlled by infectious $\mathrm{R}$ factors in Enterobacteriaceae. Nature, 208: 239-241. https:// doi.org/10.1038/208239a0

Dundar, D. and Otkun, M., 2010. Invitro efficacy of synergistic antibiotic combinations in multidrug resistant Pseudomonas aeruginosa strains. Yonsei. med. J., 51: 111-116. https://doi.org/10.3349/ ymj.2010.51.1.111

El-Shouny, W.A., Ali, S.S., Sun, J., Samy, S.M. and Ali, A., 2018. Drug resistance profile and molecular characterization of extended spectrum beta-lactamase (ES $\beta \mathrm{L}$ )-producing Pseudomonas aeruginosa isolated from burn wound infections. Essential oils and their potential for utilization. Microb. Pathog., 116: 301-312. https://doi. org/10.1016/j.micpath.2018.02.005

Farshadzadeh, Z., Khosravi, A.D., Alavi, S.M., Parhizgari, N. and Hoveizavi, H., 2014. Spread of extended-spectrum $\beta$-lactamase genes of blaOXA-10, blaPER-1and blaCTX-M in
Pseudomonas aeruginosa strains isolated from burn patients. Burns, 40: 1575- 1580. https://doi. org/10.1016/j.burns.2014.02.008

Ghafourian, S., Sadeghifard, N., Soheili, S. and Sekawi, Z., 2015. Extended spectrum beta lactamases: Definition, classification and epidemiology. Curr. Issues. mol. Biol., 17: 11-22.

Golshani, Z., Ahadi, A.M. and Sharifzadeh, A., 2012. Antimicrobial susceptibility pattern of Pseudomonas aeruginosa isolated from patients referring to Hospitals. Arch. Hyg. Sci., 1: 48-53.

Gupta, V., 2007. An update on newer $\beta$-lactamases. Indian J. med. Res., 126: 417-427.

Guvensen, N.C., Keskin, D. and Sankur, F., 2017. Detection and antibiotic resistance profile of Pseudomonas aeruginosa and prevalence of multiple antibiotics resistant (MAR) in different clinical isolates. Eur. J. Biotechnol. Biosci., 5: 7478.

Hancock, R.E., 1998. Resistance Mechanisms in Pseudomonas aeruginosa and other nonfermentative gram negative bacteria. Clin. Infect. Dis., 27: S93-S99. https://doi.org/10.1086/514909

Hassuna, N.A., Mohamed, A.H.I., Abo-Eleuoon, S.M., Rizk and H.A.W.A., 2015. High Prevalence of multidrug resistant Pseudomonas aeruginosa recovered from infected burn wounds in children. Arch. clin. Microbiol., 6: 1-7.

Hong, D.J., Bae, I.K., Jang, I-H., Jeong, S.H., Kang, H-K. and Lee, K., 2015. Epidemiology and characteristics of metallo- $\beta$-lactamase-producing Pseudomonas aeruginosa. Infect. Chemother., 47: 81-97. https://doi.org/10.3947/ic.2015.47.2.81

Jarlier, V., Nicolas, M.H. and Fourneir, G., 1998. Extended spectrum beta lactamases conferring transferable resistance to newer $\beta$-lactam agents in Enterobacteriaceae: Hospital prevalence and susceptibility patterns. Rev. Infect. Dis., 10: 867878. https://doi.org/10.1093/clinids/10.4.867

Khanfar, H.S., Bindayna, K.M., Senok, A.C. and Botta, G.A., 2009. Extended spectrum beta-lactamases (ESBL) in E. coli and K. pneumoniae: trends in the hospital and community settings. J. Infect. Dev. Ctries., 3: 295-299.

Knothe, H., Shah, P., Krcmery, V., Antal, M. and Mitsuhashi, S., 1983. Transferable resistance to cefotaxime, cefoxitin, cefamandole and cefuroxime in clinical isolates of Klebsiella pneumoniae and Serratia marcescens. Infection, 11: 315-317. https://doi.org/10.1007/BF01641355

Krumperman, P.H., 1983. Multiple antibiotic resistance indexing of Escherichia coli to identify high 
risk sources of fecal contamination of food. Appl. environ. Microbiol., 46: 165- 170. https://doi. org/10.1128/AEM.46.1.165-170.1983

Lambert, P.A., 2002. Mechanisms of antibiotic resistance in Pseudomonas aeruginosa. J. R. Soc. Med., 95: 2226.

Llanes, C., Pourcel, C., Richardot, C., Plesiat, P., Fichant, G., Cavallo, J.D. and Merens, A., 2013. Diversity of $\beta$-lactam resistance mechanisms in cystic fibrosis isolates of Pseudomonas aeruginosa: A French multicenter study. J. Antimicrob. Chemother., 68: 1763-1771. https://doi.org/10.1093/jac/dkt115

Manchanda, V. and Singh, N.P., 2003. Occurrence and detection of AmpC beta-lactamases among Gram negative clinical isolates using a modified threedimensional test at Guru Tegh Bahadur Hospital, Delhi. J. Antimicrob. Chemother., 51: 415-418. https://doi.org/10.1093/jac/dkg098

Mesaros, N., Nordmann, P., Plesiat, P., Delvallez, M.R., Eldere, J.V., Glupczynski, Y., Laethem, Y.V., Jacobs, F., Lebecque, P., Malfroot, A., Tulkens, P.M. and Bambeke, F.V., 2007. Pseudomonas aeruginosa: resistance and therapeutic options at the turn of the new millennium. Clin. Microbiol. Infect., 13: 560-578. https://doi.org/10.1111/j.14690691.2007.01681.x

Naas, T., Poirel, L. and Nordmann, P., 2008. Minor extended-spectrum $\beta$-lactamases. Clin. Microbiol. Infect., 14: 42-52. https://doi.org/10.1111/j.14690691.2007.01861.x

Neyestanaki, D.K., Mirsalehian, A., Rezagholizadeh, F., Jabalameli, F., Taherikalani, M. and Emaneini, M., 2014. Determination of extended spectrum beta-lactamases, metallo-beta lactamases and AmpC-beta-lactamases among carbapenem resistant Pseudomonas aeruginosa isolated from burn patients. Burns, 40: 1556-1561. https://doi. org/10.1016/j.burns.2014.02.010

Nordmann, P. and Naas, T., 1994. Sequence analysis of PER-1 extended-spectrum beta-lactamase from Pseudomonas aeruginosa and comparison with class A beta-lactamases. Antimicrob. Agents Chemother., 38: 104-114. https://doi.org/10.1128/AAC.38.1.104

Odumosu, B.T., Adeniyi, B.A. and Chandra, R., 2016. First detection of OXA-10 extended-spectrum betalactamases and the occurrence of mexR and nfxB in clinical isolates of Pseudomonas aeruginosa from Nigeria. Chemotherapy, 61: 87-92. https://doi. org/10.1159/000441712

Opus, A., Yildirim, T., Birinci, A. and Durupinar, B., 2017. Investigation of the relationship between class-1 integrons and per-1 enzyme in ceftazidime resistant Pseudomonas aeruginosa. Biomed. Res., 28: 2689-2695.

Parija, S.C., 2006. Textbook of practical microbiology. $1^{\text {st }}$ edition, 184-185.

Paterson, D.L. and Bonomo, R.A., 2005. Extendedspectrum beta-lactamases: A clinical update. Clin. Microbiol. Rev., 18: 657-686. https://doi. org/10.1128/CMR.18.4.657-686.2005

Pathmanathan, S.G., Samat, N.A. and Mohamed, R., 2009. Antimicrobial susceptibility of clinical isolates of Pseudomonas aeruginosa from a Malaysian Hospital. Malays. J. med. Sci., 16: 27-32.

Paul, S., Bezbaruah, R.L., Roy, M.K. and Ghosh, A.C., 1997. Multiple antibiotic resistance (MAR) index and its reversion in Pseudomonas aeruginosa. Lett. appl. Microbiol., 24: 169-171. https://doi. org/10.1046/j.1472-765X.1997.00364.x

Peerayeh, S.N., Mahabadi, R.P., Toupkanlou, S.P. and Siadat, S.D., 2014. Diversity of $\beta$ - lactamases produced by imipenem resistant, Pseudomonas aeruginosa isolates from the bloodstream. Burns, 40: 1360-1364. https://doi.org/10.1016/j. burns.2014.01.009

Peymani, A., Naserpour-Farivar, T., Zare, E. and Azarhoosh, K.H., 2017. Distribution of blaTEM, blaSHV, and blaCTX-M genes among ESBLproducing $P$. aeruginosa isolated from Qazvin and Tehran hospitals, Iran. J. Prev. Med. Hyg., 58: E155-E160.

Poirel, L., Girlich, D., Naas, T. and Nordmann, P., 2001. OXA-28, an extended-spectrum variant of OXA-10 beta-lactamase from Pseudomonas aeruginosa and its plasmid-and integron-located gene. Antimicrob. Agents Chemother., 45: 447-453. https://doi. org/10.1128/AAC.45.2.447-453.2001

Polotto, M., Casella, T., de Lucca Oliveira, M.G., Rubio, F.G., Nogueira, M.L., de Almeida, M.T. and Nogueira, M.C., 2012. Detection of Pseudomonas aeruginosa harboring blaCTX-M-2, blaGES-1 and blaGES-5, blaIMP-1 and blaSPM-1 causing infections in Brazilian tertiary-care hospital. BMC Infect. Dis., 12: 176. https://doi.org/10.1186/14712334-12-176

Qing, Y., Cao, K.Y., Fang, Z.L., Huang, Y.M., Zhang, X.F., Tian, G.B. and Huang, X., 2014. Outbreak of PER-1 and diversity of $\beta$-lactamases among ceftazidime-resistant Pseudomonas aeruginosa clinical isolates. J. med. Microbiol., 63: 386-392. https://doi.org/10.1099/jmm.0.069427-0

Salverda, M.L., De Visser, J.A. and Barlow, M., 2010. Natural evolution of TEM-1b-lactamase: experimental reconstruction and clinical relevance. 
FEMS Microbiol. Rev., 34: 1015-1036. https://doi. org/10.1111/j.1574-6976.2010.00222.x

Sandhu, R., Dahiya, S. and Sayal, P., 2016. Evaluation of multiple antibiotic resistance (MAR) index and Doxycycline susceptibility of Acinetobacter species among inpatients. Indian J. Microbiol. Res., 3: 299-304. https://doi.org/10.5958/23945478.2016.00064.9

Shahid, M., Malik, A. and Sheeba., 2003. Multidrugresistant Pseudomonas aeruginosa strains harbouring R-plasmids and AmpCL-lactamases isolated from hospitalized burn patients in a tertiary care hospital of North India. FEMS Microbiol. Lett., 228: 181-186. https://doi.org/10.1016/S03781097(03)00756-0

Shaikh, S., Fatima, J., Shakil, S., Rizvi, S.M.D. and Kamal, M.A., 2015. Prevalence of multidrug resistant and extended spectrum beta-lactamase producing Pseudomonas aeruginosa in a tertiary care hospital. Saudi J. biol. Sci., 22: 62-64. https:// doi.org/10.1016/j.sjbs.2014.06.001

Srikumar, R., Tsang, E. and Poole, K., 1999. Contribution of the MexAB-OprM multidrug efflux system to the beta-lactam resistance of penicillin-binding protein and beta-lactamase-derepressed mutants of Pseudomonas aeruginosa. J. Antimicrob. Chemother., 44: 537-540. https://doi.org/10.1093/ $\mathrm{jac} / 44.4 .537$
Toupkanlou, S.P., Peerayeh, S.N. and Mahabadi, R.P., 2015. Class A and D extended spectrum beta lactamases in imipenem resistant Pseudomonas aeruginosa isolated from burn patients in Iran. Jundishapur J. Microbiol., 8: e18352. https://doi. org/10.5812/jjm.18352v2

Ullah, F., Malik, S.A. and Ahmed, J., 2009. Antimicrobial susceptibility and ESBL prevalence in Pseudomonas aeruginosa isolated from burn patients in the North West of Pakistan. Burns, 35: 1020-1025. https://doi. org/10.1016/j.burns.2009.01.005

Weldhagen, G.F., Poirel, L. and Nordmann, P., 2003. Ambler class A extended-spectrum beta-lactamases in Pseudomonas aeruginosa: novel developments and clinical impact. Antimicrob. Agents Chemother., 47: 2385-2392. https://doi.org/10.1128/ AAC.47.8.2385-2392.2003

Zhao, W.H. and Hu, Z.Q., 2010. Beta lactamases identified in clinical isolates of Pseudomonas aeruginosa. Crit. Rev. Microbiol., 36: 245-258. https://doi.org/10 $.3109 / 1040841$ X.2010.481763

Ziha-Zarifi, I., Llanes, C., Kohler, T., Pechere, J.C. and Plesiat, P., 1999. In vivo emergence of multidrugresistant mutants of Pseudomonas aeruginosa overexpressing the active efflux system MexAMexB-OprM. Antimicrob. Agents Chemother., 43: 287-291. https://doi.org/10.1128/AAC.43.2.287 